\title{
Diplomacia y misión en Europa durante la guerra de Sucesión: los Habsburgo-Wolfenbüttel, el Estado de Milán y el catolicismo septentrional*
}

\author{
Roberto Quirós Rosado**
}

Recibido: 21 de octubre de 2015 / Aceptado: 31 de marzo de 2016

Resumen. Las perspectivas geopolíticas de la guerra de Sucesión española traspasaron ampliamente los límites de la herencia territorial de Carlos II. El político enlace del candidato austriaco al trono de Madrid, Carlos III de Austria, con Isabel Cristina de Braunschweig-Wolfenbüttel, una princesa luterana convertida ex profeso al catolicismo, vinculó las dos dinastías con el esfuerzo misionero de la Santa Sede en el norte del Sacro Imperio. En el presente estudio se propone reconstruir la relación de la red diplomática Wolfenbüttel con el papado y la monarquía carolina, además de apuntar la difusa — pero constante- presencia de la soberana dentro del proceso de financiación lombarda del misionalismo germánico a comienzos del Setecientos.

Palabras clave: Carlos VI de Habsburgo; Isabel Cristina de Braunschweig-Wolfenbüttel; Sacro Imperio Romano Germánico; Guerra de Sucesión Española; misiones católicas.

\section{[en] Diplomacy and Mission in Europe during the War of the Spanish Succession: Habsburg-Wolfenbüttel Dinasties, the State of Milan and the Northern Catholicism}

\begin{abstract}
The geopolitical perspectives of the War of the Spanish Succession went beyond the limits of Charles II's territorial heritage. The marriage between Charles of Habsburg with Elizabeth Christine of Braunschweig-Wolfenbüttel, a Lutheran princess converted to the Catholicism, linked both dynasties with the missionary effort of the Holy See in the Holy Empire. This paper is focuses on the Wolfenbüttel diplomatic network with the Papacy and the Habsburg monarchy in Vienna, Barcelona and Milan, as well as on the role of the Queen-Empress in this confessional project.
\end{abstract}

Keywords: Charles VI of Habsburg; Elizabeth Christine of Braunschweig-Wolfenbüttel; Holy Roman Empire; War of the Spanish Succession; Catholic Missions.

\footnotetext{
* El presente estudio se ha realizado al amparo del Programa Propio para la Formación del Personal Investigador de la Universidad Autónoma de Madrid (FPI-UAM), dentro de la investigación doctoral titulada Constantia et fortitudine. La corte de Carlos III y el gobierno de Italia, 1706-1714. Tesis doctoral inédita, Madrid, Universidad Autónoma de Madrid, 2015, bajo la supervisión del profesor Dr. Antonio Álvarez-Ossorio Alvariño (UAM); asimismo, se ha ampliado dentro del proyecto de la Dirección General de Investigación del Ministerio de Economía y Competitividad Sociedad cortesana y redes diplomáticas: la proyección europea de la monarquía de España (1659-1725) [HAR2015-67069-P (MINECO/FEDER)].

** Universidad Autónoma de Madrid. roberto.quiros@alumni.uam.es
} 
Sumario. 1. Las Missioni Settentrionali y el ducado de Braunschweig-Wolfenbüttel en el contexto de la guerra de Sucesión española. 2. Entre razón de religión y razón de estado. La lombardía de los Habsburgo y la misión de Wolfenbüttel. 3. Conclusión.

Cómo citar: Quiros Rosado, R. (2016), Diplomacia y misión en Europa durante la Guerra de Sucesión: los Habsburgo-Wolfenbüttel, el estado de Milán y el catolicismo septentrional, en Cuadernos de Historia Moderna 41(1), 29-47.

La construcción de la majestad de Carlos III de Austria fue un fenómeno marcado por su intrínseca complejidad. La problemática sucesión del trono hispano truncó las expectativas del emperador Leopoldo I para consolidar la monarquía de España dentro de la Casa de Austria. Su negativa a reconocer a Felipe V de Borbón, nieto de Luis XIV, como rey de España tuvo como consecuencia directa el estallido de un nuevo conflicto dinástico que llevó a la guerra abierta a las principales potencias europeas del momento. La proclamación del archiduque Carlos, segundogénito del césar, como soberano español tuvo lugar en Viena en septiembre de 1703. Desde el mismo momento de la cesión del ius hispanicus al príncipe Carlos de Austria, se dio comienzo a un periplo político que le llevaría a éste a peregrinar por la Europa en conflicto para alcanzar la península Ibérica y reclamar sus derechos al solio de Madrid ${ }^{1}$.

La política tejida desde la corte vienesa con las Potencias Marítimas, Saboya y Portugal también generó una ramificación diplomática tendente a consolidar la progenie de don Carlos, inicialmente con la princesa portuguesa Teresa de Bragança. Tras la repentina muerte de ésta en 1704, las opciones matrimoniales italianas y germánicas fueron las preferidas por Leopoldo y su sucesor José. Pese a las esperanzas puestas por Viena, pronto fracasó la negociación con Wilhelmina Charlotte de Brandenburg-Ansbach, quien rehusó a abjurar de su fe reformada². Desechadas otras

\footnotetext{
Sobre el conflicto sucesorio sucesivo a la muerte de Carlos II y la configuración de la Gran Alianza de La Haya, que articularía la oposición contra Luis XIV y Felipe V, véase FreY, L. y M.: A Question of Empire: Leopold I and the War of the Spanish Succession, 1701-1705, Nueva York, Columbia University Press, 1983; RiBot GaRCÍA, L. A.: "La presencia de la Monarquía de los Austrias en Italia a finales del siglo XVII", en ALCALÁ-ZAMORA y Queipo de Llano, J. y Belenguer CebriÀ, E. (coords.): Calderón de la Barca y la España del Barroco, vol. I, Madrid, Centro de Estudios Políticos y Constitucionales, 2001, pp. 975-995; OchoA Brun, M. A.: Embajadas rivales. La presencia diplomática de España durante la guerra de Sucesión, Madrid, Real Academia de la Historia, 2002; Riвot García, L. A.: Orígenes políticos del testamento de Carlos II. La gestación del cambio dinástico en España, Madrid, Real Academia de la Historia, 2010; y, como introducción a la problemática "archiduquista" en Madrid y Milán antes de 1700, Quirós RosADO, R.: "«Hault et puissant Prince, mon très cher et très aymé bon cousin et nepveu». El archiduque Carlos y la Monarquía de España (1685-1700)", Mediterranea. Ricerche storiche, 33 (abril 2015), pp. 47-78.

2 Ingrao, Ch. W.: In Quest and Crisis. Emperor Joseph I and the Habsburg Monarchy, East Lafayette, Purdue University Press, 1979, pp. 173-175. León SANZ, V.: "Jornada a Barcelona de Isabel Cristina de Brunswick, esposa del archiduque Carlos (1708)", Estudis, 33 (2007), pp. 93-114: 95. Cabe resaltar la inexistencia de una monografía sobre la reina-emperatriz Isabel Cristina, tanto en la historiografía española como en la centroeuropea. Junto a la citada obra de Virginia León, existen semblanzas de la soberana en otras obras de conjunto sobre el papel de las reinas (y sus damas más cercanas) en la España de comienzos del Setecientos, caso de la obra de Pérez Samper, Ma . Á.: Poder y seducción. Grandes damas de 1700, Madrid, Temas de Historia, 2003, o el estudio monográfico de León SAnz, V.: El archiduque y los austracistas. Guerra de Sucesión y exilio, San Cugat del Vallés, Arpegio, 2014; o el ensayo de GonzÁlez Cruz, D.: "Actitudes e imágenes de las reinas en tiempos de crisis: la transición de los Austrias a los Borbones", en González Cruz, D. (ed.): Virgenes, reinas y santas. Modelos de mujer en el mundo hispánico, Huelva, Publicaciones de la Universidad de Huelva, 2007, pp. 73-104. Asimismo, para el plano analítico del papel de las reinas de España durante la Modernidad, es preciso referir los volúmenes colectivos de LóPez-Cordón Cortezo, M. ${ }^{a}$ V. y Franco RuBio, G. (coords.): La reina Isabel y las reinas de España: realidad, modelos e imagen historiográfica, Madrid, Fundación Española de Historia Moderna, 2005, y Martínez Millán, J. y Lourenço, Mª P. Marçal
} 
candidaturas, el nuevo césar José I alcanzó una solución favorable a su política de reforzamiento de la autoridad cesárea sobre el Sacro Imperio. La elegida fue la princesa Isabel Cristina de Braunschweig-Wolfenbüttel, nieta del duque reinante Anton Ulrich. Su familia, luterana desde comienzos del siglo XVI, no vio con malos ojos el enlace con el monarca hispano, máxime cuando una estrecha pariente, Amalia de Braunschweig-Lüneburg, ya había desposado años atrás con el propio emperador

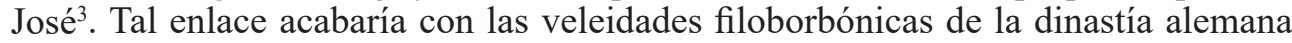
e, incluso, unificó los intereses confesionales de Wolfenbüttel, Viena, Barcelona y la mismísima corte de Roma en medio de un conflicto que hacía tiempo había dejado de ser meramente dinástico, sino abiertamente basado en intereses geoestratégicos, mercantiles y, pese a la creciente secularización de las relaciones exteriores, religioso ${ }^{4}$.

\section{Las Missioni Settentrionali y el ducado de Braunschweig-Wolfenbüttel en el contexto de la guerra de Sucesión española}

El matrimonio entre el rey Carlos y la princesa de Braunschweig-Wolfenbüttel fue gestionado durante los años 1705 y 1706 sin intervención directa del soberano español. El artífice del mismo tampoco provenía de la corte carolina de Barcelona, sino de la de Viena. Se trataba del padre teatino Amadeus Hamilton. Católico inglés de ilustre familia escocesa, desde su juventud realizó diversas estancias en Múnich y Praga, antes de ser electo como preboste en la Theatinerkirche vienesa, a la par que su hermano Charles Hamilton ejercía la representación diplomática jacobita ante el emperador ${ }^{5}$. A comienzos de la centuria se embarcó en las misiones de la India y Persia, pero su periplo no duró mucho, recalando nuevamente en la corte cesárea y, de allí, a la legación extraordinaria en Wolfenbüttel ${ }^{6}$.

La estancia de Hamilton en los estados del duque Anton Ulrich coincidió con la de Ludolf Wilhelm Majus, un antiguo alumno del romano Collegio Urbano, el

(coords.): Las relaciones discretas entre las Monarquías Hispana y Portuguesa. Las Casas de las reinas (siglos XV-XIX), 3 vols., Madrid, Polifemo, 2009.

3 Sobre el papel político del duque Anton Ulrich a comienzos de la guerra de Sucesión española, desde su posicionamiento filo-borbónico hasta su acercamiento a los Habsburgo, véase LuCKHARDT, J. (ed.): “... einer der grösten Monarchen Europas"?!. Neu Forschungen zu Herzog Anton Ulrich, Petersberg, Michael Imhof Verlag, 2014.

$4 \quad$ Nuevas lecturas en torno a la transición entre los siglos XVII y XVIII en el marco confesional de la diplomacia y la guerra han ido perfilándose a partir de los estudios monográficos y colectivos de HuEY BoLES JR, L.: The huguenots, the protestant interest, and the war of the Spanish succession, 1702-1714, Nueva York, P. Lang, 1997; GonzÁlez CRUz, D.: Guerra de religión entre príncipes católicos. El discurso del cambio dinástico en España y América (1700-1714), Madrid, Ministerio de Defensa, 2002; y Civale, G. (ed.): Predicazione, eserciti e violenza nell'Europa delle guerre di religione (1560-1715), Turín, Claudiana, 2014. Asimismo, para indagar en las nuevas líneas metodológicas de interpretación del conflicto sucesorio español, véase CRESPO SOLANA, A. y Schmidt-Voges, I. (eds.): New Worlds? Transformations in the culture of international relation c. 1713, Aldershot, Ashgate, 2016, en prensa.

5 Borromeo, A. M.: De electione vocalis inter Clericos Regulares comitiis generalibus interfuturi. Qucestiones practica, Roma, Typis Antonii de Rubeis, 1712, p. 44. Otro estrecho pariente suyo, el conde Johann Andreas von Hamilton, sirvió paralelamente en los ejércitos de José I y Carlos III en Lombardía y Cataluña. Quirós Rosado, R.: "Por el rey de España y la Augustísima Casa. Los regimientos italianos de Carlos III de Austria en Cataluña (1705-1713)", en Blanco NúÑ̃Z, J. Ma . (coord.), Revista Internacional de Historia Militar, 94 (2016), pp. 21-37.

6 Mathee, R. (intr.): A chronicle of the Carmelites in Persia, Londres, Tauris \& Co., 2012, p. 534; Theiner, A.: Storia del ritorno alla Chiesa Cattolica delle Case regnanti di Brunswich e di Sassonia, Roma, coi Tipi della S. Congregazione di Propaganda Fide, 1849, p. 8. 
epicentro de la formación misionera de la Congregación de Propaganda Fide. Majus acababa de ser enviado por el dicasterio pontificio a su Alemania natal, ejerciendo su labor evangélica en Braunschweig. Un informe remitido a Roma en el invierno de 1706 da cuenta del estado del catolicismo local, muy vinculado a la comunidad mercantil compuesta por un centenar de italianos, franceses y alemanes. El culto de los criptocatólicos, al contrario que en otros principados cercanos, comenzaba a ser amparado por el potentado local. Se beneficiaron de su tolerancia para "che siano serviti nello spirituale in una segreta cappella da un sacerdote". Junto a las críticas de predicadores luteranos, el mayor problema radicaba en el escaso conocimiento de la lengua alemana por el único cura católico, un fraile franciscano, que le impedía catequizar y confesar a los fieles autóctonos. Por ello, las peticiones reformadoras de Majus, quien se supo granjear el favor de la feligresía de Wolfenbüttel, facilitaron la resolución de Propaganda de conceder al vicario apostólico Otto Wilhelm von Bronckhorst, obispo in partibus de Columbica, la potestad de destinar religiosos a la misión y conceder pequeñas pensiones cuando se considerase oportuno ${ }^{7}$.

Las prendas de Majus llegaron a oídos del duque de Braunschweig, el cual no dudó en recomendar encarecidamente a Propaganda Fide un puesto estable ante sí mismo. El favor ducal hacia el misionero hacía conveniente su permanencia en la corte alemana, máxime ante los guiños amistosos del soberano a los católicos asentados en sus estados. El proselitismo abierto gracias a una mayor libertad confesional en Wolfenbüttel y la propia implicación personal del papa Clemente XI favorecieron la continuidad de Majus en sus cometidos ${ }^{8}$.

La permanencia de Ludolf Wilhelm Majus en la corte del duque Anton Ulrich evoca la voluntad romana de secundar un incipiente proceso de recuperación para la Santa Sede de principados germánicos reformados. Como ya sucediera casi un siglo atrás en el caso de Neoburgo, y más recientemente con el duque Augusto de Sajonia tras su ascenso al solio polaco, la restauración del catolicismo en tierras septentrionales parecía ir de la mano de la conversión de los príncipes territoriales. La fórmula de status quo reconocida en los congresos de Westfalia (1648), "Cuius regio, eius religio", podría beneficiar la penetración del catolicismo tridentino más allá de los lugares que la Compañía de Jesús y los efectos de la política confesional de la Casa de Habsburgo habían alcanzado9. Sin embargo, no desde la Urbs, sino desde la propia ciudad de Wolfenbüttel comenzó a gestarse una dinámica tendente a catalizar los esfuerzos de particulares, seglares y laicos, cuyas prácticas intenta-

Congregación general de Propaganda Fide, Roma, 8 de febrero de 1706. Archivio Storico di Propaganda Fide (ASPF), Acta, 76, fols. 16r-v.

8 A la par, se solventó el espinoso asunto de la servidumbre del misionero, juramentado previamente ante la Sagrada Congregación, al servicio de un "principe heretico" como era el duque de Braunschweig-Wolfenbüttel. Congregación general de Propaganda Fide, Roma, 6 de septiembre de 1706. ASPF, Acta, 76, fols. 252v-254v.

9 Una bibliografía actualizada sobre la historia del catolicismo principesco en el Sacro Imperio de la Edad Moderna se encuentra registrada en SchNetTGer, M.: "Die römische Kurie und die Fürstenkonversionen Wahrnehmung und Handlusngsstrategien", en Matheus, R., Oy-Marra, E. y Pietschmann, K. (eds.): Barocke Bekehrungen. Konversionsszenarien im Rom der Frühen Neuzeit, Bielefeld, Transcript Verlag, 2013, pp. 117-148: 142-148. Para una aproximación teórica sobre la "construcción" del Norte/Septentrión en la política confesional de la Monarquía de España bajo el reinado de Carlos II, véase Bravo Lozano, C.: “¿Antemural de la fe o tierras de misión? Reflexiones en torno al Norte y la proyección confesional de la Monarquía Católica, 1665-1700", en García Martín, P., Quirós Rosado, R. y Bravo Lozano, C. (eds.): Antemurales de la fe. Conflictividad confesional en la monarquía de los Habsburgo, 1516-1714, Madrid, Ministerio de Defensa. UAM Ediciones, 2015, pp. 213-240. 
ban lograr la tolerancia religiosa hacia la fe católica y su rearticulación jerárquica e institucional ${ }^{10}$.

El buen éxito de las negociaciones matrimoniales entre Carlos III de Austria y la princesa Isabel Cristina de Braunschweig-Wolfenbüttel favorecieron la consolidación del catolicismo nórdico. Aprovechando tal contexto, la febril actividad del misionero Majus, buen conocedor de la geopolítica principesca alemana, fue tenida muy en cuenta en Propaganda Fide. El dicasterio romano debatió sus propuestas sobre la división del vicariato apostólico de las Missioni Settentrionali en dos cabezas. Dicha idea ya había sido consultada en verano de 1706, tras la determinación de Clemente XI de honrar al abate veneciano Agostino Steffani con una prelacía. Dicho religioso, misionero, músico y diplomático cesáreo con una larga trayectoria en el Sacro Imperio, fue provisto con el obispado in partibus de Pegæ, si bien su promoción hacia mayores oficios en tierras alemanas dependía de la resolución de su superior, el ya citado obispo de Columbica $^{11}$. Von Bronckhorst ejercía como vicario desde 1702 bajo la estrecha supervisión del nuncio apostólico en Colonia. Su reticencia a perder parte de la jurisdicción encomendada mantuvo paralizada cualquier medida que pudiera favorecer a Steffani y su colaborador Majus. En febrero de 1707, este último remitió un nuevo memorial a Propaganda incidiendo en las posibilidades que facilitara la exaltación de Steffani y la orientación misionera de los novicios radicados en los monasterios agustinos, benedictinos y bernardos de las diócesis de Ildesheim y Halberstadt. Sus pingües rentas podían financiar los estudios de dichos jóvenes en el Collegio Urbano y en otros seminarios misioneros, con lo que la política confesional pontificia en la Alemania protestante se vería sumamente beneficiada. El proyecto de Majus fue aceptado sin reticencia alguna por Propaganda, cuyos miembros encomendaron al nuncio colonense, Giambattista Bussi, la ejecución de órdenes tendentes a la captación de novicios y monasterios para la causa misionera y la definitiva división del vicariato, siempre y cuando alcanzase un acuerdo con el obispo de Columbica ${ }^{12}$.

Mientras se ponían en marcha las disposiciones de la Sagrada Congregación, Ludolf Wilhelm Majus continuó su labor pastoral siéndole encomendada la asistencia en materia espiritual de la futura reina de España. Una vez signado el convenio matrimonial entre los representantes cesáreos y los duques de Wolfenbüttel, el primer día de mayo de 1707 la princesa Isabel Cristina abjuró su fe luterana en la catedral de Bamberg, en manos del elector y arzobispo de Maguncia (Mainz), barón Lothar Franz von Schönborn, a la sazón, vicecanciller del Imperio ${ }^{13}$. Tras su conversión, la princesa pasó a habitar temporalmente en la corte de Viena. Allí prosiguió su instrucción católica bajo la dirección del misionero Majus y su formación en lengua castellana

10 Sobre el impacto de las misiones amparadas por Propaganda Fide en el Septentrión durante el siglo XVII, véase PIEPER, P. A.: Die Propaganda-Congregation und die nordischen Missionen im siebenzehnten Jahrhundert, Colonia, Verlag von J. P. Bachem, 1886. Hasta finales del Seiscientos gran parte del esfuerzo de conservación del catolicismo en tierras germánicas dependía de los electores-arzobispos de Colonia, Maguncia y Tréveris, verdaderos potentados y gestores de los intereses pontificios en los antemurales romanos frente al luteranismo y el calvinismo. Una reciente monografía sobre dichos aspectos se corresponde con Braun, B.: Princeps et episcopus. Studien zur Funktion und zum Selbstverständnis der nordwestdeutschen Fürstbischöfe nach dem Westfälischen Frieden, Göttingen-Bristol, Vandenhoeck \& Ruprecht, 2013.

11 El breve de nombramiento de la sede titular de Steffani data de 13 de septiembre de 1706, mientras la consagración episcopal tuvo lugar en la iglesia jesuita de Bamberg, en manos del arzobispo-elector de Maguncia. Una breve semblanza del prelado veneciano, desde la óptica religiosa, se encuentra en KoHL, W. (ed.): Germania Sacra. Bistum Münster, 7. Die Diözose, vol. IV, Berlín, De Gruyter, 2004, pp. 74-77.

12 Congregación general de Propaganda Fide, Roma, 14 de marzo de 1707. ASPF, Acta, 77, fols. 71r-72r.

13 TheINER, op. cit. (nota 6), p. 6. 
con el antiguo oficial de la embajada española en la corte Habsburgo, Francisco Pérez de Segura ${ }^{14}$. La estancia vienesa sembró dudas sobre la continuidad del ejercicio misionero católico en el ducado de Braunschweig. Majus intentó por distintas vías regresar a la corte ducal, pese a intentársele convencer por agentes imperiales de la necesidad de mantenerse al servicio de la futura reina de España ${ }^{15}$. Ante la disyuntiva de proseguir el viaje de la soberana hacia la península Ibérica o mantenerse en Alemania ejerciendo "sua vocatione", Majus logró la dispensación de Isabel Cristina para retornar junto al duque Anton Ulrich y mantener su activa labor proselitista ${ }^{16}$.

El catolicismo de la princesa conversa tomó corporeidad durante su periodo vienés. Los avisos impresos y manuscritos hacen constante hincapié en su participación en ceremonias eclesiásticas de corte. La pietas austriaca le fue inculcada por sus nuevos parientes, haciéndola propia con rapidez. Noticias coetáneas aluden, incluso, a la instauración de una nueva orden de caballería, la del Amor al Prójimo, poco antes de su partida de Viena ${ }^{17}$. El reconocimiento definitivo de la princesa, tanto de su nuevo estatus regio, como de su fe católica, tuvo lugar durante el casamiento por poderes con Carlos III y en los actos de despedida de la familia imperial. Durante todo su viaje por Austria, Tirol y Lombardía, Isabel Cristina asistió devotamente a los oficios en diversos monasterios masculinos y femeninos —en la abadía de Melk hizo "la sua devozione [...] sotto l'Esposizione del Santissimo"- e incluso puso la primera piedra de un cenobio de carmelitas en una localidad austriaca ${ }^{18}$.

Regresando al Septentrión, la definitiva consolidación de Majus como gestor del catolicismo local tuvo lugar en los años 1708 y 1709, una vez había sido investido con una canonjía de la catedral de Hildesheim. Revestido de dicha prebenda, continuó remitiendo informes a Propaganda Fide sobre la reactivación de comunidades criptocatólicas en los estados del duque Anton Ulrich y de la ciudad libre de Goslar, protegida por dicho potentado ${ }^{19}$. Sus ordinarias epístolas también dan cuenta de la lenta

14 Pérez de Segura, tras ejercer dicha labor pedagógica no sólo en Viena sino durante todo el viaje a Barcelona e, incluso, ya residiendo la soberana junto con su marido, fue agraciado con una plaza de oficial en la secretaría de Flandes y con el empleo, futurario, de archivero del Archivo de Simancas. Privilegio de Carlos III a Francisco Pérez de Segura, Barcelona, 2 de septiembre de 1709. Archivo Histórico Nacional (AHN), Estado, legajo 8688.

15 El misionero Majus dio cuenta a Propaganda Fide de la primicia sobre la voluntad de la princesa Isabel Cristina para marchar a Viena, tras ser "ad Romanam Ecclesiam conversam”. Carta de Ludolf Wilhelm Majus a Propaganda Fide, Braunschweig, 7 de febrero de 1707. ASPF, Scritture riferite nei Congressi. Germania e Missioni Settentrionali, 3, fols. 279r-280r.

16 Congregación general de Propaganda Fide, Roma, 22 de agosto de 1707. ASPF, Acta, 77, fols. 281r-282r. Congregación general de Propaganda Fide, Roma, 14 de noviembre de 1707. Ibídem, fols. 402v-402r.

17 Según el cronista setecentista Ferdinand Ludwig von Bressler y el predicador Johann Gottfried Oertel, su divisa de la Orden era un lazo rojo con una cruz áurea pendente sobre el pecho, cuyo lema era Amor proximi. BRESSLER UND Aschenburg, F. L. von: Les souverains du monde, tomo IV, París, chez Guillaume Cavelier, fils, 1718 , pp. 347-348; Oertel, Johann Gottfried, Castrum doloris in templo Honoris Divo Carolo VI Rom. Imp. Regi Catholico Hisp. Hung \& Boh. Archi-Duci Austriae reliqua Sacrum, Oedenburg, gedrucht ben Johann Philipp Rennauer, 1740, s. p., nota U.

18 Avisos, Viena, 5 de mayo de 1708. Foglio aggiunto all'Ordinario. 5 Maggio 1708, Viena, appresso Giovanni van Ghelen, 1708. Los detalles de la ceremonia nupcial de Isabel Cristina y Carlos III —representado por su hermano el emperador - celebrada por el también converso cardenal de Sajonia son aportadas por el embajador extraordinario portugués conde de Vilar Maior. Carta del conde de Vilar Maior al conde de Assumar, Viena, 28 de abril de 1708. Biblioteca Nacional de España (BNE), Ms. 7544, fols. 19r-v. Relación portuguesa del matrimonio de Carlos III e Isabel Cristina de Braunschweig-Wolfenbüttel, sin lugar, ni fecha [Viena, fines de abril de 1708]. Ibidem, fols. 55r-56r.

19 Congregación general de Propaganda Fide, Roma, 27 de marzo de 1708. ASPF, Acta, 78, fols. 177v-178v. Aprovechando su fluida correspondencia con Roma, solicitó a Propaganda Fide la aceptación en el Collegio Urbano de un sobrino suyo, "levato alla sua sorella heretica per aducarlo nella nostra Santa Fede", según se había prometido desde el propio dicasterio. Congregación general de Propaganda Fide, Roma, 26 de septiembre de 1708. Ibidem, fol. 657r. 
llegada de misioneros a tierras ducales, alcanzándose el número de tres sacerdotes, entre ellos el español doctor Llimargas, profesor de lengua castellana en la "Accademia Ducale". A la par, avisan de la estrecha vinculación entre el canónigo y el principal diplomático del duque, el barón Rudolf Christian von Imhof, recientemente convertido al catolicismo ${ }^{20}$. La autonomía adquirida por el misionero pervivió pese a la división del vicariato de las Misiones Septentrionales, concediéndose al abate Steffani el rango de vicario apostólico en las tierras dependientes del marqués de Brandemburgo (no reconocido por Roma como rey de Prusia), de los duques de Braunschweig-Lüneburg y Braunschweig-Wolfenbüttel, del elector Palatino y las comunidades no sujetas a jerarquías episcopales ${ }^{21}$.

La voluntad clementina para dinamizar la política confesional romana en el Septentrión cristalizó una vez el duque Anton Ulrich decidiera convertirse al catolicismo. Fruto de la labor del misionero Majus y del diplomático Amadeus Hamilton, la conversio parecía inminente una vez quedó establecida una continua relación epistolar entre el potentado alemán y el pontífice. La buena acogida del papa Clemente hacia la tolerancia de los católicos de Wolfenbüttel debió impulsar al duque a aceptar el catolicismo como fe personal, pero no de sus estados. El proceso catequético de Anton Ulrich von Braunschweig-Wolfenbüttel se realizó bajo un atento seguimiento de Majus y del mencionado arzobispo-elector de Maguncia. La ceremonia solemne de conversión, celebrada en secreto en el palacio ducal, tuvo lugar en 10 de enero de $1710^{22}$.

Acogido entre la grey católica, el duque buscó el apoyo del emperador José I para dar continuidad a las prácticas proselitistas que habían comenzado bajo su amparo. El encargado de gestionar dichos tratos fue Ludolf Wilhelm Majus, quien se dirigió a Roma para solicitar nuevas fuentes de financiación del renacido catolicismo en los estados de Wolfenbüttel. Las instancias de Majus y del embajador imperial, marqués de Priero, dieron rápido sus frutos ${ }^{23}$. El interés de Roma por ganarse la confianza del duque Anton Ulrich traspasó el mero negociado diplomático de ambos sujetos. La liberalidad de Clemente XI se manifestó, incluso, con el envío de un cuadro del afamado pintor romano Carlo Maratta como regalo al duque converso ${ }^{24}$. Máxime, se barajó la posibilidad de concederle un capelo cardenalicio si por su confesión católica

20 Carta de Ludolf Wilhelm Majus a Silvio De Cavalieri, secretario de Propaganda Fide, Hildesheim, 13 de septiembre de 1709. ASPF, Scritture riferite nei Congressi. Germania e Missioni Settentrionali, 3, fols. 373r-375v.

21 La decisión pontificia, aceptada por Propaganda Fide, fue comunicada sin posibilidad de mutación al nuncio en Colonia y al obispo de Columbica. Congregación general de Propaganda Fide, Roma, 26 de marzo de 1709. ASPF, Congregazioni particolari, 70, fols. 1r-2r. Sobre las jurisdicciones septentrionales y la tipología del catolicismo local, véase Memoria sobre las Misiones Septentrionales. sin lugar, ni fecha [Roma, 1709]. Ibidem, Congregazioni particolari, 70 , fols. $7 \mathrm{r}-12 \mathrm{v}$.

22 Breve de Clemente XI al duque de Braunschweig-Wolfenbüttel, Roma, 10 de enero de 1709. ASPF, Scritture riferite nei Congressi. Germania e Missioni Settentrionali, 3, fols. 213r-214v. TheIner, op. cit. (nota 6), p. 9. El duque renovó la profesión de fe en manos del elector de Maguncia, Lothar Franz von Schönborn, en el mes de abril de 1710. Ibidem, p. 18.

23 Theiner, op. cit. (nota 6), p. 10. Por contra, fracasaron los intentos del duque Anton Ulrich por ver al padre Hamilton investido "col titolo di vescovo in partibus, dipendente però del metropolitano, et ordinario, per poter'esercitare le funzioni vescovali nelli suoi paesi”. El pontífice agradeció la voluntad y celo del potentado alemán, pero le conminó a que la jurisdicción del catolicismo de Wolfenbüttel continuase bajo los obispos de Columbica y Pegæ. Carta del duque de Braunschweig-Wolfenbüttel a Clemente XI, Braunschweig, 8 de noviembre de 1710. Archivio Segreto Vaticano (ASV), Segreteria di Stato. Principi, 140, fols. 377r-v. Carta del cardenal de Sajonia a Silvio De Cavalieri, Bratislava, 26 de noviembre de 1710. ASPF, Scritture riferite nei Congressi. Germania e Missioni Settentrionali, 3, fols. 546r-v. Breve de Clemente XI al duque de Braunschweig-Wolfenbüttel, Roma, 24 de enero de 1711. Ibídem, fols. 552r-553r.

24 Carta de Ludolf Wilhelm Majus a Silvio De Cavalieri, Hildesheim, 19 de junio de 1710. ASPF, Scritture riferite nei Congressi. Germania e Missioni Settentrionali, 3, fols. 482r-483v. 
hubiera de abandonar la potestas de su ducado ${ }^{25}$. Más allá de presentes y un hipotético cardenalato, la cancillería vaticana no cejó en buscar remedios a la financiación de la parroquia católica proyectada en Braunschweig y de la misión activada en 1706. Reiteradas órdenes de Propaganda Fide instaron a los diplomáticos pontificios en Viena, el nuncio Piazza y el internuncio y nepote pontificio Annibale Albani, a encontrar sacerdotes capacitados para ejercer "le missioni apostoliche nelle parti settentrionali, e particolarmente negli Stati del signor Duca di Brunsvich"26. Por su parte, en carta al obispo Steffani, Majus reconoció el empeño personal del duque en erigir la parroquia al otorgar mil cuatrocientos táleros. Según palabras expresas del potentado, "li altri cattolici devono essere più liberali colla mano, che colla bocca"27. Para paliar dicha escasez financiera, desde la corte papal se remitió una buona limosna a cargo del papa, a la par que se decidió a otorgar unas rentas fijas que podrían coadyuvar a la falta de liquidez para la obra constructiva ${ }^{28}$. La finca donde se había de situar la merced se encontraba dentro de las jurisdicciones del rey Carlos III, el esposo de Isabel Cristina de Braunschweig-Wolfenbüttel: la abadía cremonesa de San Pietro y San Paolo de Barbata, en el Estado de Milán.

\section{Entre razón de religión y razón de estado. La Lombardía de los Habsburgo y la misión de Wolfenbüttel}

Mientras comenzaban los preparativos de la partida del rey Carlos hacia Italia y el Sacro Imperio para solicitar el título imperial, vacante por el deceso de José I, Carlos III remitió al gobernador general de Milán un despacho urgente. En él se ordenaba la inmediata ejecución del placet a las bulas de la abadía de Barbata que le habrían sido presentadas por el enviado Imhof. La aplicación del decreto sería inminente, "no obstante mis reales órdenes que a ello puedan oponerse, pues las notorias y especiales circunstancias que en esse caso concurren procede assí de mi real voluntad"29.

Las reales órdenes impedían, de iure, la aprobación regio-ducal a las bulas de provisión de abadías y beneficios eclesiásticos en el Estado de Milán. Desde el tiempo de los Visconti y los Sforza, los duques milaneses se abrogaron la gestión de las rentas eclesiásticas vacantes en tierras lombardas, organizándose en tiempos del último Sforza el Economato Regio Apostolico. Tras un siglo de vida, en 1641 el Economato fue dotado de instrucciones privativas, que le convertían en pieza clave en la concesión o negación del placet a los nombramientos pontificios en los territorios bajo la jurisdicción milanesa ${ }^{30}$. La mayor autoridad de dicha institución tuvo lugar a comienzos del

25 Carta de la secretaría de Estado pontificia a Annibale Albani, Roma, 12 de abril de 1710. ASV, Segreteria di Stato. Germania, 49-A, fols. 19v-20v.

26 Carta de Annibale Albani al cardenal Giuseppe Sacripante, Viena, 26 de abril de 1710. ASPF, Scritture riferite nei Congressi. Germania e Missioni Settentrionali, 3, fol. 440r.

27 Carta de Ludolf Wilhelm Majus a Agostino Steffani, Hildesheim, 24 de junio de 1710. ASPF, Scritture riferite nei Congressi. Germania e Missioni Settentrionali, 3, fol. 498r.

28 Carta de Ludolf Wilhelm Majus a Silvio De Cavalieri, Hildesheim, 20 de agosto de 1710. ASPF, Scritture riferite nei Congressi. Germania e Missioni Settentrionali, 3, fols. 532r-533r.

29 Despacho de Carlos III al príncipe Eugenio de Saboya, Barcelona, 26 de agosto de 1711. ASMi, Dispacci Reali, cartella 146.

30 Una reciente monografía sobre dicha institución político-religiosa se corresponde a Dell'Oro, G.: Il Regio Economato. Il controllo statale sul clero nella Lombardia asburgica e nei domini sabaudi, Milán, Franco Angeli, 2007. 
reinado de Carlos III, como consecuencia directa del enfrentamiento diplomático entre los dos soberanos Habsburgo con la Santa Sede por el reconocimiento monárquico hacia el primero. En marzo de 1708 llegaron al ecónomo regio Francesco Visconti órdenes desde Barcelona para que se llamasen a todos los eclesiásticos con beneficios y cargos dentro de tal iurisdictio. En caso de recusación, la pena estipulaba la privación de los frutos de los beneficios y demás rentas eclesiásticas del Estado. Asimismo, se decretó la prohibición de saca de moneda fuera de Milán y la limitación de la aprobación soberana hacia aquellas nóminas romanas que no correspondiesen a sujetos de naturaleza lombarda ${ }^{31}$.

El caso del duque de Braunschweig-Wolfenbüttel hacía prácticamente imposible el beneplácito regio hacia el privilegio concedido a su persona por Clemente XI, al menos haciendo valer el imperium legis. Sin embargo, el estrecho parentesco entre el beneficiario y el rey Carlos y el objetivo final de la concesión pontificia anuló cualquier oposición al placet. Superada dicha traba ejecutiva, sólo restaba encomendar la administración y cobro de las rentas abaciales a un sujeto capacitado y leal al duque Anton Ulrich. Aunque éste ya había contactado previamente con diferentes nobles lombardos, caso del conde Carlo Molinari, enviado cesáreo-católico en Génova ${ }^{32}$, el elegido para gestionar Barbata fue Antonio Maria Melzi.

La familia Melzi era conocida en la metrópoli ambrosiana, aunque su fortuna era relativamente reciente. El abuelo del representante ducal era feudatario de Mozzanica desde 1650 , y dos décadas y media después logró la investidura de Chieveso y un título marquesal otorgado por el duque de Saboya Vittorio Amedeo II. Su heredero fue el marqués Egidio Maria Melzi, quien perteneció al Consiglio Generale y alcanzó el oficio de inspector regio en el Estado de Milán, falleciendo en 1693 como consecuencia de las heridas mortales recibidas durante la batalla de Orbassano. De su enlace con Anna Rosales, viuda del conde Ottavio Caccia e hija del conocido ministro jenízaro Mateo Ordoño de Rosales, conde de Vailate y marqués de Castelleone, tuvo a dos vástagos varones, Gaspare Antonio y Antonio Maria ${ }^{33}$.

La notable parentela familiar y los servicios hechos por el marqués Egidio Maria a la monarquía de España facilitaron la inserción definitiva de los Melzi en las estructuras del patriciado y el clero lombardo. En 1699, Gaspare accedió al Colegio de

31 Carta del abate Clemente Mandosi al cardenal Fabrizio Paolucci, Milán, 24 de marzo de 1708. ASV, Fondo Albani, 80, fol. 12r. Avisos, Milán, 24 de marzo de 1708. Ibidem, fols. 31v-32r. Una profundización de la conflictividad suscitada en la Italia carolina como consecuencia de la presión diplomática a la Santa Sede en los años 1708-1709 aparece en Quirós Rosado, R.: “Que le permite la potestad económica que Dios le ha dado. Patronato regio y redes cortesanas en la Italia austriaca, 1706-1714", Annali di Storia Moderna e Contemporanea - Nuova serie, en prensa.

32 Cartas del conde Carlo Molinari al duque de Braunschweig-Wolfenbüttel, Génova, 6 de marzo y 2 de mayo de 1709. Archivio di Stato di Milano (ASMi), Carteggi Consolari, cartella 8, pp. 44 y 96. Sobre la prácticamente desconocida figura del avisado Molinari, véase Ferorelli, N.: "Il carteggio Molinari sull'Austria in Italia dal 1705 al 1718", Annuario del Regio Archivio di Stato in Milano, 8 (1918), pp. 49-91.

33 Teatro genealogico delle famiglie nobili milanesi (edición de C. Cremonini), vol. II, Mantua, Gianluigi Arcari Editore, 2003, p. 87. Asimismo, sobre las elites lombardas, tanto del antiguo patriciado como advenedizas, véase el reciente estudio de Cremonini, C.: Le vie della distinzione. Società, potere e cultura a Milano tra XVe XVIII secolo, Milán, EDUCatt, 2012, o el estudio comparativo de las categorías nobiliarias italianas de DONATI, C.: "The Italian Nobilities in the Seventeenth and Eighteenth Centuries", en ScotT, H. M. (ed.), The European Nobilities in the Seventeenth and Eighteenth Centuries, vol. I, Londres-Nueva York, Longman, 1995, pp. 237-268. Sobre el concepto social "jenízaro", es decir, hijos de españoles e italianos, véase ÁlvarEZ-Ossorio Alvariño, A.: "Naciones mixtas. Los jenízaros en el gobierno de Italia", en Álvarez-Ossorio Alvariño, A. y García García, B. J. (eds.): La monarquía de las naciones. Patria, nación y naturaleza en la monarquía de España, Madrid, Fundación Carlos de Amberes, 2004, pp. 597-652 
Jurisconsultos de Milán, corporación elitista de los letrados del Estado, así como a una futura de cuestor de capa y espada en el magistrado Ordinario cuatro años después. La recomendación del gobernador general príncipe de Vaudémont y el desembolso de 2.000 reales de plata castellanos en Madrid, una cantidad exigua para las experiencias venales precedentes, le sirvió para alcanzar el ejercicio del oficio, "pero sin goce hasta entrar en la propiedad de los del número", en $1705^{34}$.

El desplome de la Lombardía borbónica tras la batalla de Turín, en septiembre de 1706, supuso un serio contratiempo para las aspiraciones ministeriales del casato Melzi. Junto a la invalidación de las mercedes hechas en tiempo de Felipe V, los excesos cometidos por los criados del hermano menor, Antonio Maria Melzi, abad de San Simone e Giuda, fueron incoados por el Senado y una junta ex profeso de altos magistrados milaneses ${ }^{35}$. Por suerte para los hermanos, el abate contaba con un poderoso valedor. El retorno del Estado de Milán a los Habsburgo había supuesto la reapertura de las relaciones diplomáticas tejidas tiempo atrás por los electores del Palatinado y que se mantuvieron vigentes que el estallido de la guerra de Sucesión española y la caída en desgracia de su titular, el regente marqués Cesare Pagani ${ }^{36}$. El elector Johann Wilhelm del Palatinado-Neoburgo consideró pertinente continuar la residencia diplomática en la ciudad de Milán, eligiendo para ello al abate Antonio Maria Melzi, pariente del citado regente y reputado como un sujeto fiel a la Casa de Austria ${ }^{37}$. Usando dicha representación, el residente palatino Melzi sirvió a la futura esposa de Carlos III, Isabel Cristina de Braunschweig-Wolfenbüttel, exponiendo al público "bella livrea di panno verde galonato d'oro con molti staffieri" en el paso de aquélla por

34 Teatro genealogico (nota 33), vol. II, p. 87. Privilegio de Felipe V a favor del marqués Gaspare Antonio Melzi, Madrid, 28 de diciembre de 1703. ASMi, Registri delle Cancellerie dello Stato. Serie II. Privilegi e patenti, cartella 37, fols. 2r-3r. Despacho de la reina gobernadora María Luisa de Saboya al príncipe de Vaudémont, Madrid, 7 de marzo de 1706. Ibídem, fols. 3r-v. Un marco general sobre la venalidad lombarda, en Álvarez-Ossorio Alvariño, A.: "La venalidad de magistraturas en el Estado de Milán durante el reinado de Carlos II", Archivio Storico Lombardo. Serie XII, 6 (2000), pp. 111-261.

35 Acuerdo de la junta sobre el "abbate Melzo", Milán, 28 de junio de 1708. ASMi, Uffici Regi. Parte antica, cartella 148. Estaba compuesta por el marqués Pirro Visconti, gran canciller; el conde Luca Pertusati, presidente del Senado; el marqués Giorgio Clerici, presidente del magistrado Ordinario; el senador Luigi Caroelli y el abogado fiscal Joseph de Araciel. En ella se dudaba sobre la implicación del abate Melzi en una refriega entre sus criados y los "sbirri di compagna"; por ello, el gran canciller Visconti fue encargado de "parlare in buona forma al medesimo abbate Melzi conforme la mente della medesima Gionta".

36 Durante las últimas décadas del reinado de Carlos II, el servicio ministerial de don Cesare —quien llegó a alcanzar el grado de regente provincial lombardo en el consejo supremo de Italia- le convertía en una pieza clave para los posibles intereses de la dinastía germánica en el estratégico Milán. Una consulta de dicho dicasterio, de 1692, se hizo eco del reconocimiento de Pagani como tal residente, juzgándose por innecesaria e, incluso, incompatible "exerzer dos jurisdiciones y representaziones tan opuestas", la española y la palatina. Posiblemente, la influencia de Mariana de Neoburgo, consorte del Rey Católico, permitió que se mantuviese la ocupación del marqués de forma vitalicia, si bien se presuponía que él mismo habría influido en la decisión que el elector Johann Wilhelm usase de sus servicios. Consulta del consejo supremo de Italia (Madrid, 26 de febrero de 1692). Archivo General de Simancas (AGS), Secretarías Provinciales, legajo 2073, expediente 35.

37 Para profundizar en el perfil político y cultural de Pagani, véase Cremonini, C.: "Pagani, Cesare", en Dizionario Biografico degli Italiani, vol. LXXX, 2014 [www.treccani.it/enciclopedia/cesare-pagani_\%28Dizionario_Biografico\%29/ [consultado en 15 de febrero de 2016]; y FACCHIN, L.: "Committenze artistiche e suggestioni 'libertine': il caso del marchese Cesare Pagani”, en Beniscelli, A., Magnani, L. y Spiriti, A. (eds.), Pensiero anticonformista e libertinismo erudito nel Seicento. Il crocevia genovese, Manziana, Vecchiarelli Editore, 2014, pp. 265-300. Una sintética revisión de la política diplomática de la casa germánica del Palatinado-Neoburgo a lo largo del Seiscientos se halla en Schmidt, H.: "Das Haus Pfalz-Neuburg in der europäischen Politik des 17. Jahrunderts", Mannheimer Hefte, 2 (1992), pp. 106-120. Asimismo, en la perspectiva de las dinámicas matrimoniales de la casa germánica con las principales dinastías europeas (Habsburgos madrileños y vieneses, Bragança o Farnese), véase Schmid, J. J.: "Beau-père de l'Europe: les princesses dans la politique familiale de Philippe Guillaume de Neubourg”, XVII' siècle, 243 (2009), pp. 267-280. 
suelo lombardo. Gracias a ello, logró que su hermano Gaspare siguiera a la flamante reina de España hacia la corte de Barcelona, donde alcanzó el puesto militar de veedor general del Estado de Milán ${ }^{38}$.

Los servicios de un vasallo lombardo al elector Palatino, así como los beneficios pecuniarios que pudieran reportar a su titular, motivaron una dura queja por parte del gobernador general príncipe Eugenio de Saboya y del Magistrado Extraordinario. Como sucediese años atrás con el marqués Pagani, los ministros regio-ducales informaron a Barcelona sobre lo inconveniente de la solicitud de la exención de los "dazii" por Melzi. La queja ministerial contra el abate fue atendida por el influyente embajador cesáreo ante Carlos III. Francesco Moles, duque de Parete, ejercía tal oficio desde mediados de 1707 y su amplia experiencia ministerial en tierras napolitanas y lombardas (donde alcanzó el grado de gran canciller) le convirtió en el canal fundamental del ejercicio político barcelonés hasta la creación de los primeros organismos colegiados de consulta al soberano en el verano de 1709. Mediante un parecer encaminado al soberano evidenció la insubsistencia de la petición del abate, dado el carácter secundario del propio residente palatino - según cita textual del conocido tratadista neerlandés Wicquefort- y la inexistencia de un interés político-económico particular que al elector del Palatinado "l'obblighi a tener ministri di tal grado". Retomando las órdenes dadas en este sentido por Carlos II y la excepción confirmada al ya difunto Pagani, el soberano español podría mantener el honor de residente al abate Antonio Maria Melzi, siempre y cuando contase con el asenso regio. Sin embargo, la inmunidad fiscal que aspiraba el religioso conformaría un perjudicial ejemplo "in una città, ove potrebbero altri insensibilmente cominciare a resistere colla forza, e non pagare i dazij". La dualidad de las materias juzgadas hacía convenir una inflexible negación a las franquezas tributarias para dicho diplomático, así como informar al elector de todas las particularidades de un caso que lesionaba las regalías carolinas ${ }^{39}$.

La negativa soberana a corresponder con la petición de Melzi se hizo efectiva en la primavera de 1709. En adelante persistirían las órdenes prohibitivas a ministros y vasallos de ejercer la representación de príncipes extranjeros, y nunca se podría permitir la exención fiscal que gozaran, según el ius gentium, los diplomáticos radicados ante el Rey Católico ${ }^{40}$. Sin duda, la resolución de Carlos III provocó un serio traspié a la incipiente carrera sociopolítica del abate, pero su constancia y la resolución de otros pleitos judiciales beneficiaron su progresiva exaltación en la vida milanesa. Las conexiones barcelonesas del abate le permitieron acceder al placet regio en la entrega de los bienes secuestrados durante un largo litigio tramitado en el Senado, beneficiándosele unas pingües rentas en el principado de Pavía ${ }^{41}$. La acumulación de bienes raíces y capital político le llevaron a ser consultado por la junta de Italia, radicada en la corte

38 El marqués Melzi tuvo que ejercer su oficio sin contar con el apoyo de la corte de Viena, ni con las simpatías del poderoso comisario general conde Giulio Visconti Borromeo. Cartas de Camillo Bondicchi a Francesco Panciatichi, Milán, 20 de junio y 19 de diciembre de 1708. Archivio di Stato di Firenze (ASF), Mediceo del Principato, filza 3227.

39 Parecer del duque de Parete a Carlos III, Barcelona, 14 de enero de 1709. Haus-, Hof- und Staatsarchiv (HHStA), Staatenabteilungen. Spanien. Diplomatische Korrespondenz, Karton 67.

40 Decreto de Carlos III al príncipe Eugenio de Saboya, Horta, 19 de abril de 1709. ASMi, Dispacci Reali, cartella 144. La orden se evacuó al Magistrado Ordinario, según decreto del gobernador general, de 20 de mayo de dicho año.

${ }^{41}$ Decreto de Carlos III al príncipe Eugenio de Saboya, Barcelona, 4 de noviembre de 1709. ASMi, Dispacci Reali, cartella 144. 
de Barcelona, para alcanzar una pensión eclesiástica en el obispado de Vigevano ${ }^{42}$. Sin embargo, su posición quedó gravemente dañada por dos sucesos acaecidos contra su persona y oficios.

Desde la conquista del Estado de Milán por las tropas cesáreas, la titularidad del oficio de correo mayor fue disputada por distintos particulares, aunque su administración fue entregada al propio abate Antonio Maria Melzi. Éste, contando con la experiencia del director Giovanni Battista Balbi, mantuvo un ministerio inferior pero de indudable importancia dada la centralidad de Milán en la escala postal de las diferentes cortes y teatros bélicos europeos ${ }^{43}$. Tras un lustro de ejercicio, a fines de 1711 los émulos de Melzi lograron poner en cuestión su honestidad. Para escuchar sus descargos se nombró al senador Joseph de Araciel, aunque éste acabó siendo recusado. Sendas consultas de los consejos de Italia y Estado encargaron la continuidad de la causa a un nuevo juez privativo, el cuestor conde Giuseppe Oppizoni ${ }^{44}$.

La continuidad en el cargo postal denota indirectamente la positiva resolución del affaire Melzi. Por contra, no logró superar otra limitación de su carácter público, pues una orden del ahora emperador Carlos VI renovó las órdenes de prohibición a "vassallos y súbditos" del ejercicio de residentes de príncipes forasteros, para que bajo ningún concepto se admitiesen tales sujetos ${ }^{45}$. La incidencia de la orden, emitida en Viena el 18 de marzo de 1712, afectó directamente a Antonio Maria Melzi y otros dos ministros residentes en Milán, los también abates Orrigone, ministro del elector de Tréveris, y Francesco Lunati Visconti, antiguo enviado del duque de Lorena en Barcelona ${ }^{46}$. Con la ejecución del decreto regio se ponía fin a sus encargos diplomáticos y a cualquier privilegio fiscal que aspirasen como tales representantes principescos. Curiosamente, fue en este contexto de tribulación para el abate cuando tuvieron lugar sus primeros contactos con el duque de Braunschweig-Wolfenbüttel.

La protección del abuelo de la reina de España perpetuó las gestiones de Melzi con soberanos forasteros. La causa directa de su elección como enviado del duque Anton Ulrich bien podría ser el buen recuerdo dejado a Isabel Cristina durante su paso por tierras lombardas. Más allá de una teórica representación diplomática, el papel del abate

42 Consulta de la junta de Italia, Barcelona, 5 de julio de 1711. HHStA, Italien Spanischer Rat. Vorträge der Zentralbehörden, Karton 7. Carlos III se conformó con el parecer de sus ministros en la concesión de 400 ducados sobre dicho obispado, el único de patronato regio-ducal en el Estado de Milán, siempre y cuando su embajador en Roma, el príncipe de Avellino, lograse "superar la dificultad de imponer sobre el referido obispado de Vegeben" tales pensiones eclesiásticas.

43 Uno de los principales sujetos del "ministerio español” en los Países Bajos carolinos, el secretario Francisco Antonio Navarro, daba cuenta del tradicional "cuydado" en la remisión de cartas entre Barcelona y Bruselas (pasando por Milán) durante el conflicto sucesorio, aunque en 1712 hubiese cierto "atrasso" en la recepción de las misivas cortesanas. Carta de Francisco Antonio Navarro a Andreas Kurz, Bruselas, 9 de junio de 1712. Archives Générales du Royaume de Belgique (AGRB), Chancellerie Autrichienne des Pays-Bas, 18.

44 Consulta del consejo supremo de Italia, Barcelona, 3 de marzo de 1712. HHStA, Italien Spanischer Rat. Vorträge der Zentralbehörden, Karton 10. En 29 de abril se habían remitido desde la corte barcelonesa las órdenes relativas al nombramiento de Oppizzoni "para que reziva la informazión que solicita el referido marqués Melzi”. Despacho de Carlos VI y, en su nombre, la gobernadora Isabel Cristina de Braunschweig-Wolfenbüttel al príncipe Eugenio de Saboya. Barcelona, 29 de abril de 1712. ASMi, Dispacci Reali, cartella 147.

45 Despacho de Carlos VI al príncipe Eugenio de Saboya, Viena, 18 de marzo de 1712. ASMi, Dispacci Reali, cartella 147. La orden fue evacuada inmediatamente al Senado y los dos magistrados lombardos por orden de la junta del Estado. Apuntamiento de la junta del Estado de Milán, Milán, 28 de marzo de 1712. ASMi, Uffici Regi. Parte antica, cartella 149.

46 Avisos, Milán, 6 de abril de 1712. ASV, Fondo Borghese, Serie IV, 250, fol. 159r. Existe constancia de la continuación de servicios del abate marqués Lunati Visconti al duque Leopoldo I de Lorena, en cuya corte residía en 1716. Fara, A., La Riviera di San Giulio Orta e Gozzano. Trattenimento storico, Novara, Tipografia di Francesco Merati, 1861, p. 253. 
se circunscribió a la administración de la pingüe abadía cremonesa de San Pietro e San Paolo. Su beneficiario, ante su naturaleza seglar y la imposibilidad de regirla personalmente, le encomendó su gestión mientras trataba de conseguir una transacción de su titularidad a su favor. El inmejorable trato de la corte pontificia hizo que el potentado germánico instara a Clemente XI la renuncia abacial en cabeza de su agente milanés. La inicial gestión fue llevada a cabo por el piamontés Ercole Turinetti, marqués de Priero y embajador cesáreo y católico en Roma, aunque fracasó por la "molta repugnanza" que el papa mostró a dicha cesión ${ }^{47}$. Dada la imposibilidad de conseguir una resolución favorable en la $U r b s$, el epicentro del negociado se trasladó a Barcelona, corte de la reina-emperatriz regente Isabel Cristina.

El proyecto concebido por el duque se articulaba en una dúplice intencionalidad. En primer lugar, el objetivo primordial era el mantenimiento pecuniario del catolicismo en los estados del duque. La construcción de una iglesia en el Ober Oschem de Braunschweig sólo podría tener lugar con una inversión continuada de rentas seguras, como las que provenían de Lombardía. Tal continuidad evitaría problemas económicos al renacido catolicismo en el ducado, incluso con la incertidumbre del futuro confesional ante la ancianidad del titular. La segunda cuestión giraba en torno al método que garantizara la gestión del capital remitido a Alemania. Como informase el barón Imhof al nuncio en Barcelona, Giorgio Spinola, la resolución más sencilla sería su entrega al abate Antonio Maria Melzi, quien se comprometía a pagar ochocientos escudos anuales de los teóricos dos mil que valdría el beneficio eclesiástico, por el tiempo que gozase la abadía ${ }^{48}$.

A lo largo del otoño e invierno de 1712-1713, la negociación de monseñor Spinola y la red Wolfenbüttel tuvo como protagonista excepcional a la propia soberana. Conocedora del impulso misionero amparado por su abuelo, no cejó en lograr un buen término a los intereses ducales. La proposición de Melzi había chocado continuamente con la negativa de Clemente XI para favorecer su promoción hacia mayores prebendas de las que previamente había alcanzado en el Estado de Milán. Una memoria remitida desde la cancillería pontificia al nuncio Spinola recordaba la inalterable protección del duque Anton Ulrich y el propio emperador hacia el abate, individuo que "non si curò di fargliene provare alcun frutto" y sujeto "che poco merita". La supuesta incompetencia o mal obrar de Melzi llevó al pontífice a pensar en un personaje bien conocido por su fidelidad a la Casa de Austria como potencial sucesor en la titularidad de la abadía de Barbata: monseñor Carlo Gaetano Stampa ${ }^{49}$.

47 Informaciones genealógicas en torno al embajador Priero y sus ramificaciones aristocráticas en el ducado de Saboya aparecen en Vitullo, F.: Una insigne casata piemontese. I Turinetti di Priero, Pertengo e Cambiano, Turín, Stabilimento grafico Tarditi, 1963. Para su gestión diplomática en Roma, clave en el reconocimiento de Carlos III como "rey católico de las Españas" por Clemente XI, véase Martín Marcos, D.: El Papado y la Guerra de Sucesión española, Madrid, Marcial Pons Historia, 2011, pp. 138-151.

48 Carta del nuncio Giorgio Spinola al cardenal Fabrizio Paolucci, Barcelona, 15 de octubre de 1712. ASV, Segreteria di Stato. Spagna, 207, fols. 316r-317r. Cabe resaltar cómo el propio Imhof gozaba en la Lombardía carolina una renta de 14.000 liras por merced soberana. Stato delle Regie Ducali Entrate Ordinarie dello Stato di Milano dell'anno 1713, sin lugar, ni fecha. ASMi, Uffici Regi. Parte antica, cartella 8. Sobre el papel político-diplomático de la nunciatura apostólica en Barcelona durante la guerra de Sucesión española, véase MARTín Marcos, op. cit. (nota 47), pp. 165-174; y Quirós Rosado, R.: "Reconstruyendo el ceremonial. Diplomacia y audiencias públicas en la corte carolina de Barcelona”, en Mollfulleda, C. y SAlLÉs, N. (eds.): Actes del Congrés Els Tractats d'Utrecht. Clarors i foscors de la pau. La resistència dels catalans, Barcelona, Museu d'Història de Catalunya. Generalitat de Catalunya. Departament de Cultura, 2015, pp. 473-478.

49 Memoria dirigida al nuncio Giorgio Spinola, sin lugar, ni fecha [Roma, noviembre de 1712]. ASV, Segreteria di Stato. Spagna, 361, fols. 110r-111r. Carta del cardenal Fabrizio Paolucci al nuncio Giorgio Spinola, Roma, 19 de noviembre de 1712. ASV, Segreteria di Stato. Spagna, 394, fols. 311r-v. 
El patricio milanés Stampa había mantenido desde hacía más de una década una intachable carrera al servicio de la Santa Sede. Laureado en Pavía en derecho civil y canónico, accedió al Colegio de Nobles Jurisconsultos en Milán y a pequeños beneficios eclesiásticos antes de promocionarse como camarero secreto del papa, prelado doméstico y referendario de la Signatura Apostólica. El favor clementino le aupó, a partir de 1706, a oficios administrativos relevantes en Romagna y Spoleto, lo que le convertía en un sujeto aceptable a la hora de gestionar la controvertida abadía cremonesa. Monseñor Stampa tampoco era un desconocido en la corte barcelonesa. Su posición social se había visto favorecida por las conspicuas carreras políticas de sus dos tíos, el virrey de Nápoles Carlo Borromeo Arese y el conde Uberto Stampa ${ }^{50}$. Este último, quien actuó como activo medianero de los intereses de su nepote, tenía una amplia presencia en los medios nobiliarios lombardos al poseer feudos, títulos comitales y amplias parentelas en el Estado. El conde había iniciado su cursus honorum en 1691, al acceder al gobierno ciudadano de su patria como decurión, para ser un lustro después promocionado al Consejo Secreto y, en 1702, remitido por Milán como enviado a París y Madrid. Asimismo, fue sido uno de los delegados milaneses en la recepción de las tropas imperiales y saboyanas en el otoño de 1706, y con posterioridad viajó a Viena y Barcelona para ver condecorada su antigua fidelidad a los Habsburgo. Alcanzó consecutivamente las dignidades de gentilhombre de cámara del emperador José I y Grande de España ad personam tras haber servido a la reina Isabel Cristina durante su estancia en Milán y viaje a España. Uberto Stampa ejerció posteriormente la embajada ordinaria carolina en Lisboa entre 1709 y 1711 y fue provisto con una plaza de consejero de Estado ${ }^{51}$. Las prendas políticas del conde y su sintonía con los intereses pontificios, poco comunes en el ministerio carolino, favorecieron la atención del nuncio y de la propia regente hacia el sobrino, a favor del cual ésta no había dudado en ejercer una intensa labor de protección desde finales de $1711^{52}$.

Sin embargo, y pese a lo que la Santa Sede había concebido inicialmente, monseñor Stampa rehusó aceptar la abadía de San Pietro e San Paolo de Barbata. El cambio de la titularidad a su favor incluso había sido admitido por el duque Anton Ulrich. El factor decisivo en la negativa del prelado lombardo parece ser el mal estado de la hacienda abacial durante la breve administración del abate Melzi. Por ello, Roma y Barcelona tuvieron que optar por una tercera vía no sólo para el futuro de Barbata, sino también en favor de Carlo Gaetano Stampa ${ }^{53}$. La resolución al doble entuerto pasó por un candidato

$50 \quad$ Teatro genealogico (nota 33), vol. II, p. 255. Para más información sobre el conde Borromeo, véase CREMONINI, C.: Ritratto politico cerimoniale con figure. Carlo Borromeo Arese e Giovanni Tapia, servitore e gentiluomo, Roma, Bulzoni, 2008.

51 Sobre sus mercedes en las dos cortes austriacas, Avisos, Milán, 17 de agosto de 1707. ASF, Mediceo del Principato, filza 3226. Carta de Camillo Bondicchi a Francesco Panciatichi, Milán, 15 de agosto de 1708. Ibídem, filza 3227. Por desgracia, no existe ningún estudio monográfico sobre el diplomático y patricio milanés en relación a la gestión de los intereses de Carlos III en la corte lisboeta. Alguna luz de encargos diplomáticos similares, aunque realizados en las cortes de Luis XIV y Felipe V en 1702, llevados a cabo por el conde Stampa y su colega Camillo degli Agosti, se encuentra en SAlomoni, A.: Memorie storico-diplomatiche degli ambasciatori, incaricati d'affari, corrispondenti, e delegati, che la città di Milano inviò a diversi suoi principi dal 1500 al 1796, Milán, dalla Tipografia Pulini al Bocchetto, 1806, pp. 399-401, y en CREMONINI, op. cit. (nota 50), p. 139, nota 256.

52 La mediación de la reina a favor de los intereses del conde Uberto Stampa y su sobrino iba orientada inicialmente al goce de las abadías vacantes de San Bassano o de Terzago. Carta del nuncio Giorgio Spinola al cardenal Fabrizio Paolucci, Barcelona, 30 de diciembre de 1711. ASV, Segreteria di Stato. Spagna, 206, fol. 350r. En la negociación barcelonesa tuvo un papel clave el secretario del Despacho, marqués de Rialp. Carta del nuncio Giorgio Spinola al cardenal Fabrizio Paolucci, Barcelona, 7 de mayo de 1712. Ibídem, 207, fols. 133r-v.

53 Carta del cardenal Fabrizio Paolucci al nuncio Giorgio Spinola, Roma, 28 de enero de 1713. ASV, Segreteria di Stato. Spagna, 361, fols. 117r-v. En relación a los intereses de monseñor Stampa, la regente Isabel Cristina llegó a mostrar 
nuevamente propuesto por la Santa Sede. Frente al recusante Stampa, el electo resultó un potente miembro de la curia apostólica, monseñor Bernardino Scotti, perteneciente a un casato de ilustre prosapia milanesa, patricia y feudal, quien convino acceder a la propuesta de Clemente $\mathrm{XI}^{54}$. Su aceptación, "mal volontieri, e solo per ubbidire a Sua Beatitudine", pareció ser más táctica que espontánea, proveniente de un personaje que ya gozaba de un amplio curriculum eclesiástico en la corte pontificia ${ }^{55}$. No en vano, Scotti ejercía desde 1711 el governatorato de Roma, tradicional antesala de la púrpura cardenalicia. $\mathrm{Su}$ asentimiento también solucionó la gracia deseada para Stampa, quien recibiría la titularidad y rentas de la abadía que hasta entonces gozaba monseñor Scotti, la de San Silano en Romagnano, en el condado de Novara. El juego de intercambio cubría las expectativas romanas y, sobre todo, garantizaba el objetivo inicial de la pensión de ochocientos escudos a favor de la iglesia de Braunschweig, beneficiada nuevamente con cuatro mil táleros alemanes por vía del depositario de la Cámara Apostólica ${ }^{56}$.

Expuesta la nueva proposición de reparto a la emperatriz, Spinola justificó ante la reina gobernadora cómo no era factible la gracia deseada por Melzi, dada la riqueza de una abadía que tradicionalmente se había entregado como premio a aquéllos ministros apostólicos que servían al Papado "con dispendio e fatica". Éstas eran prendas que se echaban en falta en el abate milanés, cuyo único mérito a los ojos de Roma era ser una criatura de los Wolfenbüttel. Aun renuente a dar por cancelada la promoción de Melzi que le encomendase su abuelo, Isabel Cristina instó a Spinola que tratase dichos pormenores con el secretario del Despacho Universal, marqués de Rialp, y con el enviado Imhof. Con el barón intentó llegar a un acuerdo definitivo, para el cual no dudó en juzgar la necesidad de salvaguardar económicamente "il servizio di Dio, e della chiesa di Bransvich" frente a las mundanas conveniencias de la hechura ducal. El diplomático alemán persistiría en la doble voluntad de su señor, pues junto a la financiación de la iglesia germánica también deseaba "far servizio, se poteva, a detto suo dipendente" $" 57$.

La sucesión de acontecimientos políticos y militares del invierno de 1712-1713 puso punto y final al complejo negociado por la abadía de Barbata. Antes que la emperatriz abandonase la corte de Barcelona para reunirse con su esposo en tierras imperiales, el cardenal Paolucci hizo llegar a la nunciatura una misiva aprobando la conducta de monseñor Spinola y esperando que la propuesta pontificia — incluyendo la limosna de cuatro mil táleros para el duque Anton Ulrich- satisficiera definitivamente los deseos del clan Wolfenbüttel $^{58}$. Monseñor Bernardino Scotti ejercería como buen pagador del duque, mientras la soberana observaría con gusto el premio a los Stampa, beneficiados con la abadía de San Silano, cuyas rentas podrían contentar al conde Uberto ${ }^{59}$.

su pesar ante el nuncio porque "sin'ora non aveva egli [Stampa] goduto alcun frutto dell'intercessione ch'a suo vantaggio aveva passate con Sua Santità”, bien con el affaire de la abadía de Barbata, bien con la concesión de dos abadías vacantes en el Estado de Milán y que fueron conferidas por el pontífice a dos cardenales. Carta del nuncio Giorgio Spinola al cardenal Fabrizio Paolucci, Barcelona, 24 de diciembre de 1712. Ibídem, 207, fols. 403r-v.

54 Teatro genealogico (nota 33), vol. II, p. 213.

55 Carta del cardenal Fabrizio Paolucci al nuncio Giorgio Spinola, Roma, 28 de enero de 1713. ASV, Segreteria di Stato. Spagna, 361, fols. $117 \mathrm{r}-\mathrm{v}$.

56 Memoria dirigida al nuncio Giorgio Spinola, sin lugar, ni fecha [Roma, noviembre de 1712]. ASV, Segreteria di Stato. Spagna, 361, fols. 110r-111r.

57 Carta del nuncio Giorgio Spinola al cardenal Fabrizio Paolucci, Barcelona, 24 de diciembre de 1712. ASV, Segreteria di Stato. Spagna, 207, fols. 407r-410r.

58 Carta del cardenal Fabrizio Paolucci al nuncio Giorgio Spinola, Roma, 28 de enero de 1713. ASV, Segreteria di Stato. Spagna, 395, fol. 23r.

59 Carta del cardenal Fabrizio Paolucci al nuncio Giorgio Spinola, Roma, 1 de abril de 1713. ASV, Segreteria di Stato. Spagna, 361, fol. 126v. Carta 


\section{Conclusión}

Finalizado el proceso de negociación de las rentas milanesas asignadas al duque de Braunschweig-Wolfenbüttel, la consolidación de la financiación del catolicismo septentrional aparecía como un hecho consumado. Inclusive, el esfuerzo económico de la Santa Sede hacia los ducados persistió inalterable pese a la muerte del duque Anton Ulrich en 27 de marzo de $1714^{60}$. La iniciativa diplomática de Carlos VI y la voluntad de Clemente XI no sólo permitió mantener los flujos de caudales remitidos desde la Lombardía austriaca, sino aumentarlos con otros trescientos escudos romanos a favor de los misioneros franciscanos recoletos de dicha misión, cargándose la cantidad sobre la abadía vacante de San Dionigio, también en el Estado de Milán ${ }^{61}$. Por su parte, la tolerancia del nuevo príncipe hacia sus súbditos romanos y los ministros apostólicos allí radicados evidenció una marcada continuidad respecto al curso del catolicismo desde un decenio atrás: antes de fallecer, Anton Ulrich había obligado a sus hijos August Wilhelm, el primogénito, y Ludwig Rudolf, progenitor de la emperatriz, consintiesen la salvaguarda del catolicismo en sus estados. Para ello, el anciano príncipe no dudó en publicar el 12 de marzo el libre ejercicio del culto romano en el ducado ${ }^{62}$.

A lo largo de todo el proceso político-confesional estudiado se puede observar una marcada intencionalidad del emperador Carlos y de su esposa Isabel Cristina por favorecer las directrices confesionales de la Santa Sede hacia el Septentrión. El beneplácito a dicho impulso romano no supuso una completa libertad de acción del pontífice en tierras germánicas, dado que la aceptación carolina hacia la salida de rentas lombardas para el Imperio llegó a generar un pseudo-patronato cesáreo del catolicismo nórdico. Esta voluntad parece reforzarse si se compara con otro proceso ciertamente similar en las formas, pero divergente en los resultados: el bloqueo del placet carolino a las pensiones de abadías milanesas que el papa Clemente XI destinase a los católicos suizos durante la guerra de Toggenburg de $1712^{63}$. Sus principales actores, medios y objetivos denotan grandes analogías. Se trataba de un negociado diplomático entre el emperador Carlos y el santo pontífice por la gestión y aprovechamiento de rentas abaciales lombardas para ser destinadas a la financiación de los combatientes romanos en su conflicto armado contra los cantones reformados. Sin embargo, la divergencia de los resultados permite entrever la voluntad política Habsburgo por controlar un patrimonio que Roma pretendía disponer a discreción para sostener sus propios frentes político-diplomáticos en los antemurales del catolicismo.

60 Según las mandas testamentarias del duque, doce mil escudos fueron repartidos a distintas instituciones y particulares religiosos, desde la iglesia de Braunschweig hasta los padres Hamilton y Majus. THEINER, op. cit. (nota 6), p. 23.

${ }_{61}$ El emperador Carlos no dudó en agilizar la concesión de su beneplácito pese a las órdenes dadas en contrario, especialmente hacia las provisiones clementinas de beneficiarios forasteros, a causa de la "solicitud y officios que en mi cesáreo nombre se han interpuesto por la mucha pobreza que padecen las referidas misiones". Despacho de Carlos VI al príncipe Eugenio de Saboya, Viena, 7 de noviembre de 1714. ASMi, Dispacci Reali, cartella 150. Dicha abadía de San Dionigio fue concedida posteriormente al cardenal Benet de Sala, de nuevo, inhibiéndose la legislación privativa dictaminada hacia los extranjeros. Despacho de Carlos VI al príncipe Eugenio de Saboya, Laxenburg, 4 de mayo de 1715. Ibídem, cartella 151.

62 Carta de Girolamo Archinto, nuncio en Colonia, al cardenal Giuseppe Sacripante, Colonia, 7 de abril de 1715. ASPF, Scritture riferite nei Congressi. Germania e Missioni Settentrionali, 4, fols. 266r-v. TheINER, op. cit. (nota 6), pp. 18-19.

${ }^{63}$ Quirós Rosado, R.: "Un antemural de la fe en tiempos de transición dinástica. Esguízaros y grisones ante la monarquía de Carlos III de Austria”, en García Martín, P., Quirós Rosado, R. y Bravo Lozano, C. (eds.): Antemurales de la fe. Conflictividad confesional en la monarquía de los Habsburgo, 1516-1714, Madrid, Ministerio de Defensa. UAM Ediciones, 2015, pp. 241-263: 254-261. 
Las relaciones económicas entre las tierras septentrionales y Lombardía no sólo facilitaron un táctico triunfo de la labor misionera amparada por Propaganda Fide, sino también consiguieron estrechar los lazos personales y dinásticos entre dos espacios tradicionalmente alejados entre sí. El papel jugado por el controvertido abate Melzi trascendió de su figura inicial de mero medianero y gestor de rentas abaciales para escalar hacia mayores dignidades merced a la protección de los Wolfenbüttel. En 1714 fue consultado a instancias del gobernador general Eugenio de Saboya para el Regio Economato, vacante por el deceso de su titular, el canónigo de la Scala Francesco Visconti64 ${ }^{6}$. El consejo supremo de España obvió la preeminencia en que aparecía en la terna del príncipe, pero la influencia de éste y un voto muy favorable del regente Ravaschiero — quien aludió a sus servicios como "embiado de la Sereníssima Casa Ubolfenpitel"- le valieron el nombramiento por Carlos VI ${ }^{65}$. Así, el abate medró hacia un puesto reputado dentro del ministerio lombardo, encargado paradójicamente de la gestión de los beneficios eclesiásticos vacantes o secuestrados. Sería el punto de partida de un fulgurante cursus honorum que convirtiera a Melzi, uno de los favoritos del príncipe Löwenstein, en regente honorario del consejo de España en Viena (1720) y se le condecorase con el título de príncipe en el reino de Nápoles (1726), siéndole mantenidas la administración general de las postas del Estado de Milán y la conservaduría general del priorato de Lombardía en la orden de Malta. El medro sociopolítico y su postrer casamiento con la condesa austriaca Renata Theresia von Harrach auparon a quien fuese un oscuro residente diplomático a la elite aristocrática de la corte de los Habsburgo ${ }^{66}$.

Por último, en los procesos de negociación política sobre la financiación del catolicismo septentrional hay que resaltar la centralidad no siempre evidente, difusa, opaca, de la reina y emperatriz Isabel Cristina de Braunschweig-Wolfenbüttel. Pese a su origen luterano y una conversión motivada por su político matrimonio, la soberana demostró un ferviente catolicismo compartido con su marido, lo que disipó cualquier duda en Roma sobre la sinceridad de la conversión. Durante su regencia en España, Isabel Cristina asumió un rol fundamental en el negociado establecido entre su también converso abuelo, su esposo y el pontífice Clemente XI. Llevó a cabo la difícil gestión de fomentar los intereses de Wolfenbüttel ante el nuncio Spinola, empeñándose en favor de elites lombardas que habían demostrado una fidelidad activa a la Casa de Austria y, especialmente, a su consorte durante los años precedentes.

Pero no sólo el catolicismo de la emperatriz y reina se desplegó en las pugnas diplomáticas. Su devoción al Santísimo Sacramento, demostrada ya en Viena y Melk en 1708,

${ }_{64}$ Tras la muerte de Visconti ya corrían voces en Viena sobre la provisión de Melzi al oficio, pese a que, según el nuncio Spinola, "non credo abbia di ecclesiastico, che la prima tonsura". Carta del nuncio Giorgio Spinola al cardenal Fabrizio Paolucci, Viena, 3 de marzo de 1714. ASV, Segreteria di Stato. Germania, 253, fols. $141 \mathrm{r}-142 \mathrm{r}$.

65 Consulta del consejo supremo de España, Viena, 23 de agosto de 1714. HHStA, Italien Spanischer Rat. Vorträge der Zentralbehörden, Karton 20. Privilegio de Carlos VI a favor del abate Antonio Maria Melzi, Viena, 12 de diciembre de 1714. ASMi, Registri delle Cancellerie dello Stato. Serie II. Privilegi e patenti, cartella 38, fols. $57 \mathrm{r}-58 \mathrm{v}$.

66 Despacho de Carlos VI al conde Girolamo Colloredo, Viena, 24 de julio de 1720. ASMi, Uffici Regi. Parte antica, cartella 42. CusANI, F.: Storia di Milano dall'origine a'nostri giorni, vol. III, Milán, presso la Libreria Pirotta, 1864. Ajello, R. (ed.): "Appendice”, en Ajello, R. (ed.): Pietro Giannone e il suo tempo, vol. II, Nápoles, Jovene Editore, 1980, pp. 513-536: 517. Asimismo, interesantes alusiones sobre el poder político alcanzado por el abate Melzi durante el gobierno del príncipe Löwenstein, se encuentran en ÁlvarEZ-Ossorio Alvariño, A.: "La Lombardía entre Felipe V y Carlos VI. El gobierno de Löwenstein", en Álvarez-Ossorio Alvariño, A.: Milán y el legado de Felipe II. Gobernadores y corte provincial en la Lombardía de los Austrias, Madrid, Sociedad Estatal para la Conmemoración de los Centenarios de Felipe II y Carlos V, 2001, pp. 255-319: 276-277, 312-313 y 317. 
persistió durante su estancia barcelonesa, denotándose un curioso mimetismo hacia la pietas de la dinastía Habsburgo, al igual que acaeció paralelamente en la corte de Felipe $\mathrm{V}^{67}$. Si en 1709 el embajador cesáreo Moles daba cuenta cómo Carlos III "fa assistere" a la reina a las mensuales procesiones sacramentales ${ }^{68}$, años después, en marzo de 1712, el propio nuncio Spinola avisó a Roma de un peculiar suceso en que intervino activamente la soberana, de cuya descripción se infiere una evidente similitud a los tradicionales actos piadosos de la Augustísima Casa para con el viático:

“Giovedì scorso la Maestà dell'Imperatrice nel tornare che facea verso la sera al Regio Palazzo, essendosi incontrata nel Santissimo Viatico, che si portava ad una moribonda, smontò subito alla prima comparsa del medesimo dalla carrozza, e postasi su la nuda terra in ginocchio senza aspettare che le fusse portato il cuscino, e scendesse il conte di Cardona suo maggiordomo per darle la mano, adorò con somma divozione il Santissimo Sagramento; indi rivratasi, l'accompagnò a piedi, portando in mano una candela che le fu presentata da un sacerdote, sino alla casa dell'inferma, avendo a tal'esempio di christiana umiltà e riverenza al pane eucaristico fatto lo stesso tutte le dame e cavalieri del regio corteggio. Sua Maestà volea salire alla camera dell'inferma, ma come non potè subito sapere la qualità del male di essa, restò alla porta della casa in ginocchio, recitando alcune preci divote sino a tanto, che calò abasso il sacerdote col Santissimo Sagramento, che dopo aver adorato di nuovo con segni di molta religiosità, volle accompagnare colla stessa divozione a piedi senza riguardo al lungo camino che gli conveniva di fare, ed alla pessima qualità delle strade, sino alla chiesa parrochiale del Pino, ove ricevette ancora la santa benedizione. Un tal'atto di pietà ha edificato sommamente questi popoli, che accompagnarono con mille benedizioni la Maestà Sua, la quale volle poi compire questa pia opera col mandare all'inferma, ch'era una povera dama vedova spagnola un buon sussidio caritativo"69.

El simbolismo del acto de Isabel Cristina repite los paradigmas de la devoción eucarística de la Casa de Austria desde los tiempos medievales del conde Rodolfo ${ }^{70}$. Si la vinculación de los Habsburgo con el Santísimo Sacramento había sido potenciada especialmente durante el reinado de Carlos II, dicho arcano político-confesional,

67 Río BARredo, Ma . J. del: "Los rituales públicos en Madrid en el cambio de dinastía (1700-1710)", en SERRANO Martín, E. (dir.), Felipe Vy su tiempo. Congreso Internacional, vol. II, Zaragoza, Institución Fernando el Católico, 2004, pp. 733-752: 742-747.

68 Carta del duque de Parete a José I, Barcelona, 4 de agosto de 1709. HHStA, Staatenabteilungen. Spanien. Diplomatische Korrespondenz, Karton 67, Konvolut 6. Asimismo, Ingrao, Ch. W. y Thomas, A. L., "Piety and power: the Empresses-Consort of the High Baroque", en CAmpbell OrR, C. (ed.): Queenship in Europe, 16601815. The role of the consort, Cambridge, Cambridge University Press, 2004, pp. 107-130: 117-122.

69 Avisos, Barcelona, 22 de marzo de 1712. ASV, Segreteria di Stato. Spagna, 207, fols. 86v-87v. Otras referencias sobre la exaltación eucarística de la soberana, en PÉREZ SAMPER, op. cit. (nota 2), p. 361.

70 Álvarez-Ossorio Alvariño, A.: "Virtud coronada: Carlos II y la piedad de la Casa de Austria", en Fernández Albaladejo, P., Martínez Millán, J. y Pinto Crespo, V. (coords.), Política, religión e inquisición en la España moderna: homenaje a Joaquín Pérez Villanueva, Madrid, Universidad Autónoma de Madrid, 1996, pp. 29-58. Ibídem: "La sacralización de la dinastía en el púlpito de la Capilla Real en tiempos de Carlos II", Criticón, 84-85 (2002), pp. 313-332. Río BARredo, Ma . J. del: "Rituals of the Viaticum: Dynasty and Community in Habsburg Madrid”, en Calaresu, M., De Vivo, F. y Rubiés, J.-P. (eds.), Exploring Cultural History. Essays in Honour of Peter Burke, Farnham-Burlington: Ashgate, 2010, pp. 55-75. GARMS-CorNIDES, E.: "Pietas Austriaca-Heiligenverehrung und Fronleichnamsprozession", 300 Jahre Karl VI. (1711-1740). Spuren der Herrschaft des 'letzten' Habsburgers, Viena, Generaldirektion des Österreichischen Staatsarchivs, 2011, pp. 185-197. 
articulador de una mímesis entre la majestad terrenal y la protección celestial, trascendía mediante un matrimonio que había ganado para la fe romana una princesa reformada. Era el metafórico triunfo de una política confesional que, más allá de la búsqueda de una sucesión dinástica, había amparado la piadosa soberana quien indirectamente se convirtió en la protectora de las misiones pontificias de las tierras del Septentrión.

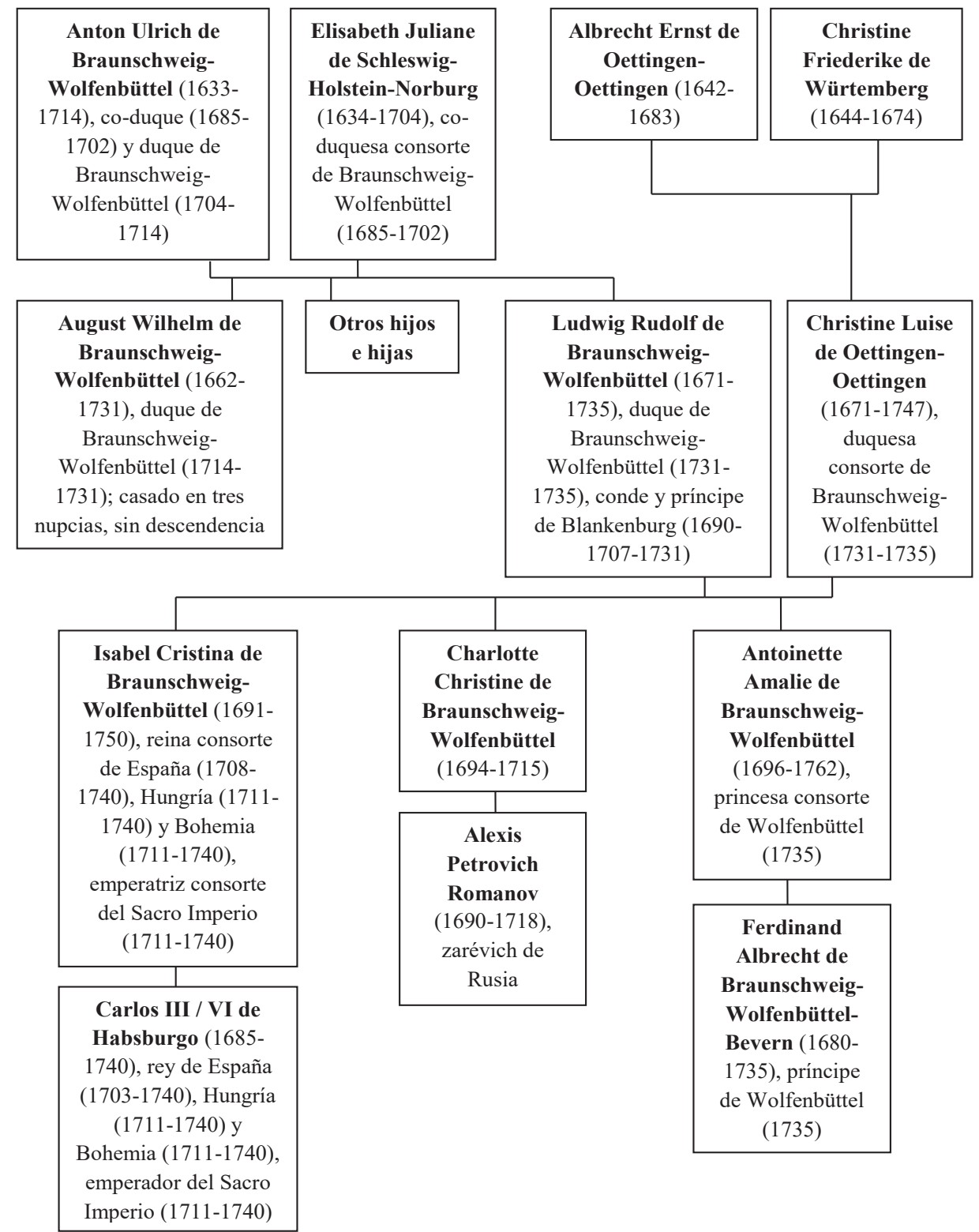

Cuadro 1. Árbol genealógico de los duques de Braunschweig-Wolfenbüttel (siglos XVIIXVIII). Elaboración propia. 